Original

\title{
Evaluating surface roughness of a polyamide denture base material in comparison with poly (methyl methacrylate)
}

\author{
Menaka A. Abuzar, Suman Bellur, Nancy Duong, Billy B. Kim, Priscilla Lu, \\ Nick Palfreyman, Dharshan Surendran and Vinh T. Tran \\ Melbourne Dental School, University of Melbourne, Melbourne, Australia
}

(Received 18 May and accepted 1 October 2010)

\begin{abstract}
Polyamide denture base materials are more flexible than the commonly used poly (methyl methacrylate) (PMMA). However polishability of polyamides has not been examined adequately. This study investigated the surface roughness ( $R a)$ and clinical acceptability of samples of a polyamide denture base material and PMMA fabricated by injection moulding and traditional heat processing systems, respectively. Half of each sample surface was polished using the conventional technique (lathe with pumice followed by high shine buffs) and the other half was left unpolished. A profilometer was used to measure Ra along 3 tracks on each surface before and after polishing. Two-way ANOVA was used to compare the two surfaces of the two materials for variations in Ra values. Polyamide denture base material when polished with conventional laboratory technique became more than 7 times smoother whereas processed PMMA when polished became more than 20 times smoother using the same polishing technique. However the surface roughness of polyamide is well within the accepted norm of $0.2 \mu \mathrm{m}$ Ra. Polyamide produces a clinically acceptable smoothness after conventional polishing by lathe. (J Oral Sci 52, 577-581, 2010)
\end{abstract}

Keywords: polyamide denture base; profilometer; surface roughness.

Correspondence to Dr. Menaka A. Abuzar, Melbourne Dental School, University of Melbourne, 720 Swanston Street, Melbourne VIC 3010, Australia

Tel: +61-3-9341-1495

Fax: +61-3-9341-1595

Email: maabuzar@unimelb.edu.au

\section{Introduction}

Poly (methyl methacrylate) (PMMA) resin has been widely used as a denture base material due to its desirable properties of excellent aesthetics, low water sorption and solubility, relative lack of toxicity, ability to repair, and simple processing techniques. Conversely some disadvantages have also been described. Hypersensitivity to PMMA and allergic reactions to residual monomer have been reported (1-6). Increased proportion of monomer in the mixture, reduced water storage phase of the polymerized denture, and chemical curing of PMMA rather than heat curing have been shown to increase the risk of residual monomer which may cause cytotoxicity in some patients (5). PMMA has a relatively low impact strength causing fractures of acrylic based dentures $(7,8)$. A clinical problem commonly encountered is the inability to choose a suitable path of insertion of PMMA removable partial dentures while maintaining close adaptation to the tissues in the presence of soft and hard tissue undercuts. Researches have attempted to improve the mechanical properties of PMMA denture bases by reinforcement with fibres (glass or carbon) and also by chemical modification $(9,10)$. Development of alternative materials such as polyamides has also been reported in the literature. In the past, these polyamides exhibited specific problems, such as warpage, water sorption, surface roughness and difficulty in polishing (11-13). Lack of chemical bonding between the base and the acrylic teeth, and the inability to reline and repair the denture also posed problems for clinicians. Modified polyamide denture base materials have become available with improved water sorption levels, and with superior flexural and impact strengths $(14,15)$. In comparison with PMMA, due to its increased flexibility, polyamide dentures 
could engage undercuts of a certain degree with improved denture retention but with less tooth modifications. It is also reported as providing overall comfort to patients $(16,17)$. It is a good alternative for patients who have sensitivity to PMMA monomer. However, due to the low melting point of polyamides, operators have found it difficult to provide a satisfactory polish. Wax-up of the denture had to be performed carefully to avoid excessive trimming by burs (13). Wet polishing is deemed necessary and even then on visual inspection the surface gloss appears less compared to the PMMA counterparts.

The surface properties of any denture base material is of particular concern as studies of denture base materials have shown a direct link between surface roughness, the accumulation of plaque and the adherence of Candida albicans $(18,19)$. Increased presence of Candida species are reported in denture related stomatitis (20). A clinically acceptable threshold level of surface roughness (Ra) of 0.2 $\mu \mathrm{m}$ where no further reduction in plaque accumulation is expected in prosthetic and dental restorative materials has been discussed in the literature (21-23). The surface roughness of dental materials including acrylic denture base materials is influenced by either mechanical or chemical polishing techniques. Mechanical polishing using abrasives is intended to produce wear of the surface in a selective controlled manner thereby reducing the surface roughness of the material (24). It has been shown that mechanical methods using pumice and lathe polishing of PMMA provides an average Ra value below the threshold of 0.2 $\mu \mathrm{m}$ (25). Berger et al. (26) have also compared several polishing techniques and concluded that the conventional polishing technique provides a better PMMA surface even though the Ra value in this study is much higher than the threshold. Wet polishing of polyamide has been recommended as necessary by the manufacturer. The present study investigated the efficacy of a standard polishing technique on the surface roughness of a polyamide and compared it with polished surfaces of PMMA.

\section{Materials and Methods}

A polyamide material (Flexiplast, Bredent $\mathrm{GmbH} \& \mathrm{Co}$ KG, Senden, Germany) was tested and compared with PMMA (Vertex RS, Vertex-Dental BV, Zeist, The Netherlands). A polyvinylsiloxane (PVS) (Extrude, Kerr Manufacturing Co, Romulus, MI, USA) mould was constructed by making an impression of two glass microscope slides glued together embedded in a plastic container. From this, a series of wax samples (Dental Wax, Lordell Trading Pty Ltd, Wetherill Park, New South Wales, Australia) were fabricated, each measuring $75 \times$ $22 \times 4 \mathrm{~mm}$. Ten samples were invested in dental stone
(Unident Yellowstone, Unident Pty Ltd, Thomas Town, VIC, Australia) and plaster (Dental Plaster, Boral Australia Gypsum Ltd, Port Melbourne, VIC, Australia), and processed in PMMA using a polymerization unit (Kavo EWL 5501, Kavo Elektrotechnisches, Leutkirch, Germany) with a short curing cycle. Another ten wax samples were similarly invested in dental stone and processed in polyamide following the manufacturer's instructions. An injection moulding machine (Polyapress, Bredent $\mathrm{GmbH}$ \& Co KG) was used with injection pressure of 720-750 $\mathrm{kPa}$ at $220^{\circ} \mathrm{C}$ and a pre-heating time of $15 \mathrm{~min}$. Any irregularities and sprues (in polyamide samples) were removed with a tungsten carbide bur (Cross-cut, coarse ISO No. 500104237065, Bredent GmbH \& Co KG) at $18,000 \mathrm{rpm}$. All samples were placed and sealed in bags containing $10 \mathrm{ml}$ water. For each specimen, half of the surface was demarcated to be maintained unpolished as a control. A PVS protective sleeve was adapted to one half of each specimen during polishing of the remaining half, to avoid any unintended surface scratches. One operator was designated to polish all samples to avoid operator variability. The conventional polishing technique was used on both the acrylic and polyamide samples.

\section{Conventional polishing}

An abrasive paper (CC768 Silicon Carbide, Deer Abrasives, Ridgefield, NJ, USA) was used on all specimens with light manual pressure. A slurry of medium grit pumice (Italian pumice, Lordell, Wetherill Park, NSW, Australia) mixed in a 1:1 ratio of water was used with a $100 \mathrm{~mm} \times$ $12.5 \mathrm{~mm}$ cloth wheel (Stitched Calico, Grobet, Carlstadt, NJ, USA) for $60 \mathrm{~s}$ at 3,000 rpm on the plishing lathe. This was repeated with fine grit pumice. A second cloth wheel, high shine buff was then used with polishing brown tripoli (Grobet, Carlstadt, NJ, USA) for $60 \mathrm{~s}$. Two $1 \times 1 \mathrm{~cm}$ samples were prepared from the centre of each polished and unpolished surface of PMMA and polyamide with a cutting disc (Laboratory Diamond Disc, Komet/Gebr. Brasseler GmbH \& Co KG, Lemgo, Germany). All samples were stored in $10 \mathrm{ml}$ water in airtight snap-lock bags. Each sample was placed in an ultrasonic bath for five min and dried using a high-pressure air hose prior to measuring surface roughness.

\section{Measuring surface roughness ( $\mathrm{Ra})$}

The surface roughness $(\mathrm{Ra})$ values were measured using a profilometer (Stylus Profiler XP-2, Ambios Technology, Santa Cruz, CA, USA) which can measure small surface variations by moving a diamond stylus in contact with the surface while moving laterally across the sample. The vertical displacement of the stylus is measured as the 
surface variations, usually measuring from $10 \mathrm{~nm}$ to $1 \mathrm{~mm}$. The height position of the diamond stylus is converted to a digital signal which is stored and displayed. The stylus tip radius of the machine used was $2.5 \mu \mathrm{m}$ with a scan length range of $0.5 \mathrm{~mm}$. Three $0.5 \mathrm{~mm}$ scans were performed on each study sample after manually approximating its centre point. A $2 \mathrm{~mm}$ distance separated each reading. The stylus was set to read at $0.20 \mathrm{~mm}$ per second with a force of 0.5 $\mathrm{mg}$ over a $100 \mu \mathrm{m}$ range. The stage of the instrument on which the specimens were mounted was manually tilted to obtain a level reading. Measurements were calculated over the entire length of the scan. Using the 'Least Squares Fit' method, the zero line was set as a baseline. The profilometer generated the Ra values for the selected areas of samples in angstroms which were converted into SI unit $\mu \mathrm{m}$. All measurements were carried out by the same researcher.

\section{Statistical analysis}

The data set constituted Ra values of 3 locations each on 10 samples for the polished and unpolished surfaces of the two materials. Two-way analysis of variance (ANOVA) was performed at $\alpha<0.01$ to evaluate and compare the two surfaces of the two materials (Polyamide and PMMA). Mean Ra values and the standard errors (SE) around the mean were also calculated. The confidence limits around the calculated means were derived using the following expression: Mean $\pm \mathrm{t}_{\alpha}(s / \sqrt{ }(\mathrm{N}-1))$. The $\mathrm{t}_{\alpha}$ is $\mathrm{t}$ value at a given confidence level (2-tailed) i.e. $0.01 ; s$ is standard deviation; and $\mathrm{N}$ denotes the number of items. The data analysis was carried out using SPSS Statistical Package (Version 18, Chicago, IL, USA).

\section{Results}

The individual Ra values when plotted show variations within the 3 locations of each sample and within the 10 samples of each of the two materials before and after polishing (Fig. 1).

The two-way ANOVA (Table 1) indicates that the Ra values varied significantly depending on the denture materials (Polyamide, PMMA) $(P<0.01)$ and the surface treatments (Unpolished and polished) $(P<0.01)$. There was no significant interaction between materials and surfaces, indicating that the effect of one factor was not dependent on the other. However the surfaces of the materials before polishing were not significantly different in terms of Ra (One-way ANOVA, $\mathrm{F}=2.235, P=0.14$ ), varying by $0.12 \mu \mathrm{m}$ on average. The polished surface of the two materials did differ significantly (One-way ANOVA, $\mathrm{F}=200.362, P<0.001)$.

The average Ra value of PMMA before polishing was $0.995 \mu \mathrm{m} \pm 0.12$ (Mean \pm S.E.) which was reduced more than 20 times to $0.046 \mu \mathrm{m} \pm 0.007$ after polishing. This level of smoothness is much lower than the accepted norm of $0.2 \mu \mathrm{m} \mathrm{Ra}$, and allows it to be used safely within the mouth and with less chances of bacterial colonization on the surface, and discomfort to the patient.

The average Ra value of the unpolished polyamide was $1.111 \mu \mathrm{m} \pm 0.178$, only about $0.12 \mu \mathrm{m}$ higher than the unpolished acrylic surface. The average Ra value of the polyamide samples after being polished with the lathe was $0.146 \mu \mathrm{m} \pm 0.018$. It is important to note that this value is also under the threshold of the accepted norm of $0.2 \mu \mathrm{m}$. This suggests that polyamide when polished with a lathe

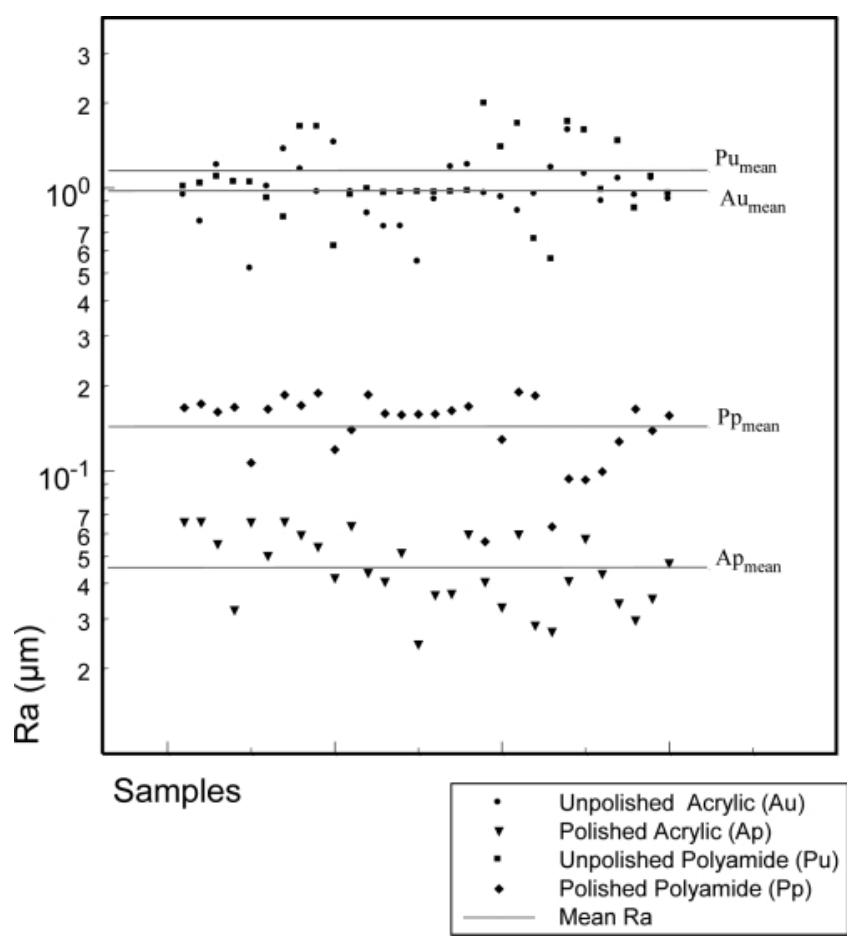

Fig. 1 Ra values measured from polished and unpolished surfaces of polyamide and acrylic samples.

Table 1 Two-way ANOVA for Ra

\begin{tabular}{lcrrrr}
\hline & Sum of Squares & $d f$ & Mean Square & \multicolumn{1}{c}{ F } & \multicolumn{1}{c}{$P$} \\
\hline Denture materials & 0.352 & 1 & 0.352 & 7.707 & 0.006 \\
Surfaces & 27.482 & 1 & 27.482 & 602.001 & $<0.001$ \\
Interaction & 0.002 & 1 & 0.002 & 0.041 & 0.840 \\
Residual & 5.296 & 116 & 0.046 & & \\
\hline
\end{tabular}


is satisfactory to be used in the oral cavity. It is notable, however, when comparing the two polished surfaces that the polished polyamide is still noticeably rougher $(>3$ times) than the acrylic after polishing but within the accepted norm for safe use.

\section{Discussion}

It is important that the surface roughness of materials used for dental prostheses are determined before their use in the mouth. Rougher surfaces can cause discoloration of the prosthesis, be a source of discomfort to patients and it may also contribute to microbial colonization and biofilm formation. Bacterial and fungal species have more of a propensity to adhere to rough denture base materials $(19,27)$. Previous studies suggest a threshold level of surface roughness of dental materials used in the oral cavity of $\mathrm{Ra}=0.2 \mu \mathrm{m}$ where no further reduction in plaque accumulation is expected under that level $(21,23,27)$. In the absence of controlled clinical studies on the surface roughness threshold for PMMA and polyamide, it was considered appropriate to accept the threshold $\mathrm{Ra}=0.2$ $\mu \mathrm{m}$ in order to explain the results of this study.

The conventional polishing technique comprising of a wet cloth wheel and a slurry of pumice followed by polishing with high shine buff produced polished acrylic and polyamide surfaces which is below the accepted threshold $(\mathrm{Ra}=0.2 \mu \mathrm{m})$. It is difficult to make direct comparisons of Ra values with other studies because of disparities in the experimental procedures, methodology used for polishing as well as measuring the surface roughness, and differences in the type of PMMA materials used. The conventional polishing technique and contact profilometers to obtain the Ra values have been used by other investigators and the results of the present study are approximately comparable and lie within the range reported $(25,28)$.

Polyamide specimens produced a rougher surface than PMMA both before and after polishing. The unpolished polyamide surface may have been affected by some degree of disintegration of the mould surface which is heated to a higher temperature than with the PMMA and also due to the pressure during injection moulding (14). The difference in Ra values of polished surfaces of PMMA and polyamide were found to be statistically significant. This may be due to the differences in the physical properties of the materials. Polyamides have been reported as being difficult to finish and polish due to their low melting temperature, and early researchers recommended careful wax-up and minimal adjustment to the dentures after processing (13). Fraying at the margins of the polyamide specimens was noticed occasionally during polishing of the samples in this study which may have occurred due to overheating of the surface and exposure of fibres. Furthermore the rate of cooling of processed polyamide affects the surface properties and it has been mentioned that very slow cooling produces a strong and relatively stiff material but also a rough surface (14). Maintenance of a smooth surface of the mould cavity would be beneficial to improve the surface quality of polyamide where trimming is not required as in clasps. The injection moulding temperature, pressure and the cooling rate has to be standardized for optimal qualities of the denture surface. The propriety nature of the ingredients used in the polyamide considered in this study makes it difficult to comment further on the influence of the chemical and physical properties on the surface roughness after polishing.

Despite the acceptable Ra value of conventionally polished polyamide as shown in this study, it is noteworthy that the polishing of this material in clinical practice would be performed in different conditions. For example, polishing is not always performed on completely flat surfaces and the recommended speed and the pressure of a rotating polisher are difficult to standardize. Therefore, a higher variability of Ra values may be expected in clinical practice. Operator variability could also occur though it was not investigated in this study. Manufacturer's recommendations for polyamide suggest the material can be used as partial denture framework including clasps, due to its flexural properties. In such a circumstance, a lathe polishing system may not be able to adequately polish all surfaces of the clasps, major and minor connectors. Further investigations with controlled load application, velocity, and duration of motion and the effect of different interfacial media (polishing pastes and liquids) are needed to improve the surface roughness of polyamides. Effects of polishing with fine diamond impregnated rubber points/cups under low pressure and the use of lubricants to minimize heat production during polishing also need to be investigated. From a material aspect the bonding of the polyamide to the matrix and the particle size itself needs to be considered. Within the limits of this study, the conventional polishing technique used for PMMA provided a polyamide surface roughness below the accepted threshold Ra value. However laboratory and clinical studies are necessary to investigate whether this is sufficient to prevent bacterial and fungal colonization of the polyamide surface.

\section{Acknowledgments}

Our thanks are due to Clay Taylor and Ronn Taylor (Technical officers, Melbourne Dental School, University of Melbourne) and Paul Jones (Technical Officer, School of Electrical and Computer Engineering, RMIT University) 
for their assistance.

\section{References}

1. Tucker TN (1981) Allergy to acrylic resin denture base. J Prosthet Dent 46, 602.

2. Basker RM, Hunter AM, Highet AS (1990) A severe asthmatic reaction to poly(methyl methacrylate) denture base resin. Br Dent J 169, 250-251.

3. Kedjarune U, Charoenworaluk N, Koontongkaew S (1999) Release of methyl methacrylate from heatcured and autopolymerized resins: cytotxicity testing related to residual monomer. Aust Dent J 44, 25-30.

4. Vilaplana J, Romaguera C, Cornellana F (1994) Contact dermatitis and adverse oral mucous membrane reactions related to the use of dental prostheses. Contact Dermatitis 30, 80-84.

5. Jorge JH, Giampaolo ET, Machado AL, Vergani CE (2003) Cytotoxicity of denture base acrylic resins: a literature review. J Prosthet Dent 90, 190193.

6. Leggat PA, Kedjarune U (2003) Toxicity of methyl methacrylate in dentistry. Int Dent J 53, 126-131.

7. Lai CP, Tsai MH, Chen M, Chang HS, Tay HH (2004) Morphology and properties of denture acrylic resins cured by microwave energy and conventional water bath. Dent Mater 20, 133-141.

8. Faot F, Costa MA, Del Bel Cury AA, Rodrigues Garcia RCM (2006) Impact strength and fracture morphology of denture acrylic resins. J Prosthet Dent 96, 367-373.

9. Jagger DC, Harrison A, Jandt KD (1999) The reinforcement of dentures. J Oral Rehabil 26, 185194.

10. John J, Gangadhar SA, Shah I (2001) Flexural strength of heat-polymerized polymethyl methacrylate denture resin reinforced with glass, aramid, or nylon fibers. J Prosthet Dent 86, 424-427.

11. Matthews E, Smith DC (1955) Nylon as a denture base material. Br Dent J 98, 231-237.

12. Watt DM (1955) Clinical assessment of nylon as a partial denture base material. Br Dent J 98, 238-244.

13. Munns D (1962) Nylon as a denture base material. Dent Pract Dent Rec 13, 142-146.

14. Hargreaves AS (1971) Nylon as a denture-base material. Dent Pract Dent Rec 22, 122-128.

15. Yunus N, Rashid AA, Azmi LL, Abu-Hassan MI (2005) Some flexural properties of a nylon denture base polymer. J Oral Rehabil 32, 65-71.

16. MacGregor AR, Graham J, Stafford GD, Huggett $R$ (1984) Recent experiences with denture polymers. J Dent 12, 146-157.
17. Stafford GD, Huggett R, MacGregor AR, Graham $\mathrm{J}$ (1986) The use of nylon as denture-base material. J Dent 14, 18-22.

18. Yamauchi M, Yamamoto K, Wakabayashi M, Kawano J (1990) In vitro adherence of microorganisms to denture base resin with different surface texture. Dent Mater J 9, 19-24.

19. Radford DR, Sweet SP, Challacombe SJ, Walter JD (1998) Adherence of Candida albicans to denturebase materials with different surface finishes. J Dent 26, 577-583.

20. Barbeau J, Séguin J, Goulet JP, de Koninck L, Avon SL, Lalonde B, Rompré P, Deslauriers N (2003) Reassessing the presence of Candida albicans in denture-related stomatitis. Oral Surg Oral Med Oral Pathol Oral Radiol Endod 95, 51-59.

21. Bollen CML, Papaioannou W, van Eldere J, Schepers E, Quirynen M, van Steenberghe D (1996) The influence of abutment surface roughness on plaque accumulation and peri-implant mucositis. Clin Oral Implants Res 7, 201-211.

22. Quirynen M, Bollen CML, Papaioannou W, van Eldere J, van Steenberghe D (1996) The influence of titanium abutment surface roughness on plaque accumulation and gingivitis: short-term observations. Int J Oral Maxillofac Implants 11, 169-178.

23. Bollen CML, Lambrechts P, Quirynen M (1997) Comparison of surface roughness of oral hard materials to the threshold surface roughness for bacterial plaque retention: a review of the literature. Dent Mater 13, 258-269.

24. Jefferies SR (2007) Abrasive finishing and polishing in restorative dentistry: a state-of-the-art review. Dent Clin North Am 51, 379-397.

25. Kuhar M, Funduk N (2005) Effects of polishing techniques on the surface roughness of acrylic denture base resins. J Prosthet Dent 93, 76-85.

26. Berger JC, Driscoll CF, Romberg E, Lou Q, Thompson G (2006) Surface roughness of denture base acrylic resins after processing and after polishing. J Prosthodont 15, 180-186.

27. Quirynen M, Marechal M, Busscher HJ, Weerkamp AH, Darius PL, van Steenberghe D (1990) The influence of surface free energy and surface roughness on early plaque formation: an in vivo study in man. J Clin Periodontol 17, 138-144.

28. Oliveira LV, Mesquita MF, Henriques GEP, Consani RLX, Fragoso WSF (2008) Effect of polishing technique and brushing on surface roughness of acrylic resins. J Prosthodont 17, 308-311. 